\title{
Anticipation of Student Ideas in Designing Sierpinsky Square Batik
} Using Maple

\author{
Erfan Yudianto \\ Universitas Jember \\ *erfanyudi@unej.ac.id
}

Received: December 2020; Accepted: December 2020; Published: January 2021

\begin{abstract}
This research is motivated by the importance that students have the ability to anticipate. The anticipation skill is needed by students to complete fractal batik designs (Sierpinsky) by using maple so that the resulting ideas matches the original expected ideas. The purpose of this research is to enable students to use maple to design Sierpinsky square batik. Data in this research were collected by tests, interviews and observations. This type of research is qualitative. The results showed that students frequently used analytical and exponential anticipation skills.

Keywords: analytic anticipation, exploratory anticipation, sierpinsky, sierpinsky batik.
\end{abstract}

How to Cite: Yudianto, E. (2021). Anticipation of Student Ideas in Designing Sierpinsky Square Batik Using Maple. Journal of Medives: Journal of Mathematics Education IKIP Veteran Semarang, 5(1), 189200. 


\section{PENDAHULUAN}

Fraktal merupakan cabang geometri yang pembahasannya terkait dengan geometri Euclid dan non-Euclid. Fraktal bisa menggambarkan bentuk-bentuk di sekitar kita dan mampu juga memprediksi kejadian-kejadian alam seperti gempa bumi, sunami, curah hujan, penyakit, keindahan matematika dan unsur pola, bentuk dan rumusnya, bahkan keindahan alam semesta ini. Fraktal berasal dari bahasa latin yaitu fractus yang artinya "patah", "rusak" atau "tidak teratur" dan bisa juga diartikan sebagai memecah-mecah membuat bagian-bagian yang tidak beraturan (Yudianto, 2019). Salah satu tokoh Fraktal adalah Sierpinsky, teori yang terkenal adalah segitiga Sierpinsky dan Karpet Sierpinsky seperti terlihat pada Gambar 1.

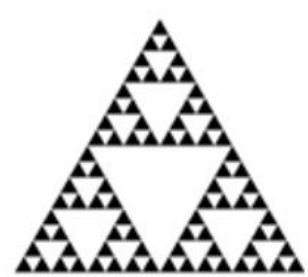

(a)

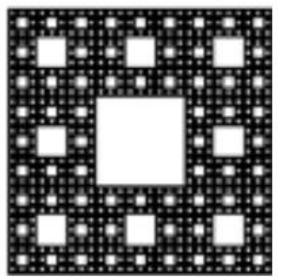

(b)
Gambar 1. (a) Segitiga Sierpinsky dan (b) Karpet Sierpinsky

Dalam penelitian ini, penerapan fraktal digunakan untuk mendesain batik bujur sangkar Sierpinsky menggunakan software Maple. Mendesain batik pada saat ini telah mengalami kemajuan dengan adanya campur tangan teknologi. Berdasarkan Observasi di daerah Jember, pembatik masih belum mengenal cara mudah dalam membuat desain menggunakan rumus-rumus matematika. Meskipun terkadang input rumus-rumus matematika ke dalam software maple cukup sulit bagi orang yang belum pernah praktik langsung. Mahasiswa sebagai calon pembawa perubahan nantinya kepada masyarakat luas, memiliki kewajiban untuk menyebarluaskan ilmu yang telah didapat selama kuliah termasuk kemandirian dalam belajar dan menyelesaikan masalah (Bramantha, 2019). Oleh karena itu diperlukan antisipasi dalam menyelesaikan masalah yang ada.

Mengantisipasi melibatkan prediksi atau peramalan. Prediksi (predicting) berasal dari kata pre yaitu sebelum dan dict (dictate) yaitu mendikte. Memiliki pengertian mendikte atau memastikan atau sudah bisa membayangkan kejadian yang belum terjadi atau memprediksi sesuatu yang akan dilakukan. Sedangkan pengertian peramalan (foreseeing) berasal dari kata fore (before) yaitu sebelum dan see yaitu melihat. Biasanya digunakan untuk menebak suatu kejadian yang akan datang, tetapi sudah dilakukan sebagian. Jadi dapat disimpulkan perbedaan dari peramalan (foreseeing) dan prediksi (predicting) adalah sama-sama bisa membayangkan kejadian yang akan datang sedangkan perbedaannya kalau peramalan (foreseeing) yaitu kejadian yang dibayangkan sudah pernah terjadi/ dilakukan sebelumnya sedangkan prediksi (predicting) belum pernah dialami sebelumnya (Lim, 2007; Rosen, 2010; Yudianto, 2017). Ini berarti prediksi adalah aktivitas mental membayangkan hasil yang akan diperoleh dari suatu kejadian tanpa melakukan serangkaian kegiatan sedangkan peramalan adalah aktivitas baik mental maupun fisik tentang langkah-langkah 
yang akan dilakukan dari suatu kejadian yang akan datang tanpa melakukan serangkaian kegiatan secara detail.

Antisipasi dibagi menjadi lima antara lain (1) antisipasi impulsif (impulsive anticipation) yaitu cara berpikir secara spontan dilanjutkan dengan suatu tindakan yang datang dalam pikiran tanpa menganalisis situasi masalah dan tanpa mempertimbangkan relevansi tindakan antisipasi suatu masalah (meramalkan secara tergesagesa); (2) antisipasi kaku (tenacious anticipation) yaitu cara berpikir seseorang dengan mempertahankan dan tidak mengevaluasi kembali cara pemahamannya (prediksi, pendekatan pemecahan masalah, klaim, atau kesimpulan) dari suatu masalah dalam mengingat informasi baru (peramalan secara kaku). Antisipasi ini disimpulkan ketika seseorang bertemu dengan informasi baru tetapi tetap pada pemahamannya sendiri yaitu dari informasi yang diberikan tanpa mempertimbangkan pendekatan alternatif dan tanpa mempertimbangkan klaim yang dipahaminya; (3) antisipasi eksploratif (explorative anticipation) yaitu cara berpikir seseorang dalam menggali ide untuk mendapatkan pemahaman yang lebih baik dari suatu masalah (mengantisipasi secara eksploratif/mau coba-coba/tidak kaku). Antisipasi ini disimpulkan ketika seseorang melakukan tindakan untuk mendapatkan penyelesaian dari suatu masalah matematika; (4) antisipasi analitik (analytic anticipation) yaitu cara berpikir seseorang dalam menganalisis masalah dan menetapkan tujuan atau kriteria untuk tindakan (mengantisipasi secara analitik/mengantisipasi berdasarkan logika/ berdasarkan analisis matematis/analisis logis). Hal ini disimpulkan ketika seseorang berusaha memahami pernyataan masalah yang diberikan, mempelajari kendala, mengidentifikasi tujuan, membayangkan masalah dan kemudian mempertimbangkan alternatif; dan (5) antisipasi terinternalisasi (interiorized anticipation) yaitu cara berpikir seseorang secara spontan dilanjutkan dengan menetapkan tujuan atau kriteria suatu masalah, karena ia telah mempertimbangkan dugaan yang relevan dari tindakan antisipasi ke situasi yang dihadapi (antisipasi yang diinternalisasi dalam pikiran). Kelima antisipasi di atas membutuhkan pema-haman yang tepat dalam pelaksanaan-nya. Hal ini dikarenakan bahwa pemahaman yang tepat akan memper-oleh hasil yang tepat (Asnawati \& Dewi, 2019; Hanifah \& Abadi, 2018; Murnaka \& Dewi, 2018; Rafianti, Iskandar, \& Haniyah, 2020; Santoso \& Sunendar, 2019).

Berdasarkan pemaparan di atas, maka masalah dalam penelitian ini adalah bagaimana antisipasi ide mahasiswa dalam mendesain batik bujur sangkar Sierpinsky menggunakan maple. Tujuannya adalah agar mahasiswa tidak mencoba-coba dalam membuat action script di maple dan memiliki kebaharuan terkait ide yang dikembangkan. Kebermanfaatan penelitian ini untuk masyarakat luas sebagai pilihan alternatif dalam mengembangkan desain batik dan untuk mahasiswa sendiri mampu mengontrol antisipasinya dalam mengerjakan desain batik yang dibutuhkan. 


\section{METODE PENELITIAN}

Penelitian ini dilakukan kepada mahasiswa Program Studi Pendidikan Matematika FKIP Universitas Jember yang menempuh matakuliah Fraktal pada tahun akademik 2020/2021 semester ganjil. Mahasiswa dipilih dari kelompok riset (KeRis) geometri. KeRis geometri bisa ditempuh pada semester 6 , dimana semua matakuliah yang dipilih adalah matakuliah dari cabang geometri (pemodelan geometri, geometri nalaria, geometri insidensi, geometri non euclid, english for writing and teaching geometri, dan geometri fraktal.

Langkah-langkah yang dilakukan dalam penentuan subjek yaitu (1) menentukan mahasiswa yang menempuh matakuliah Geometri Fraktal, hal ini diperoleh dari daftar mahasiswa yang memprogram matakuliah geometri fraktal; (2) memberikan tes kemampuan geometri, tes dikembangkan secara mandiri yang diambil dari matakuliah (geometri transformasi, geometri, geometri analitik) ditambah matakuliah Algoritma dan Pemrograman; (3) memilih mahasiswa yang memiliki kemampuan tinggi, dari hasil langkah (3) dari 30 mahasiswa diperoleh 13 mahasiswa berkemampuan geometri tinggi (skor $\geq 80$ ), 15 mahasiswa berkemampuan geometri sedang, $(70 \leq$ skor $<80)$, dan 2 mahasiswa berkemampuan geometri rendah (skor $<70)$; dan (4) memilih mahasiswa yang memiliki komunikasi lancar, kriteria lancar di sini yaitu saat diberi pertanyaan calon subjek bisa langsung merespon (tidak melihat cepet atau lambatnya dalam menyampaikan jawaban). Berdasarkan empat langkah di atas diperoleh 1 mahasiswa yang ditetapkan sebagai subjek yang dikodekan sebagai subjek 1 (S1).

Teknik pengumpulan data berupa tes, wawancara dan observasi. Instrumen yang digunakan adalah tes kemampuan geometri. Tes terdiri dari 4 soal esay seperti dijelaskan pada langkah 2 . Sebelum diberikan kepada mahasiswa, tes ini divalidasi kepada 2 orang ahli pembelajaran geometri dan denyatakan valid dengan skor 4,8 skala 5 .

Permasalahan yang diberikan kepada dua subjek adalah berupa masalah mendesain batik bujur sangkar Sierpinsky dengan bantuan software maple versi 17 dengan iterasi minimal 3.

\section{HASIL DAN PEMBAHASAN}

Hasil pekerjaan subjek dalam mendesain batik bujursangkar Sierpinsky menggunakan software maple dapat dilihat pada algoritma berikut.

\section{Background Batik}

$>$ restart; with(geom $3 d)$; with(plots); with(plottools); $>z:$

$=$ polygon $([[-100,0],[100,0],[100,100],[-100,100]]$, color $=$ "Black", style = polygon);

$>\operatorname{display}(z$, axes $=$ none $)$;

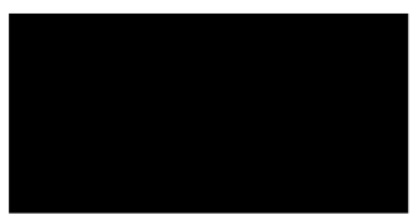

Gambar 2. Background Batik

Pada saat membuat background, subjek terlihat lancar dan tidak terkendala apa-apa. Dia juga mengetikkan action script secara manual (tidak copy paste). Hal ini sesuai dengan cuplikan wawancara berikut. 


\section{P03 : Cepat sekali buatnya mas? \\ S1-03 : Iya pak ... karena buat ini sangat mudah dan sering buat selama ini (tersenyum lalu menunduk)}

Berdasarkan hasil pekerjaan subjek dan cuplikan wawancara diperolah data yang kredibel, sehingga dapat dikatakan bahwa apa yang dikerjakan oleh subjek merupakan hal yang mudah dan bisa diterima secara nalar tanpa melakukan langkah cobacoba. Berarti antisipasi yang berperan dalam masalah ini adalah antisipasi analitik.

\section{Bujur Sangkar Sierpinsky}

S1 membuat Persegi Sierpinski, kemudian persegi Sierpinski tersebut dirotasi sebesar $45^{\circ}$ agar menjadi bujur sangkar Sierpinski.

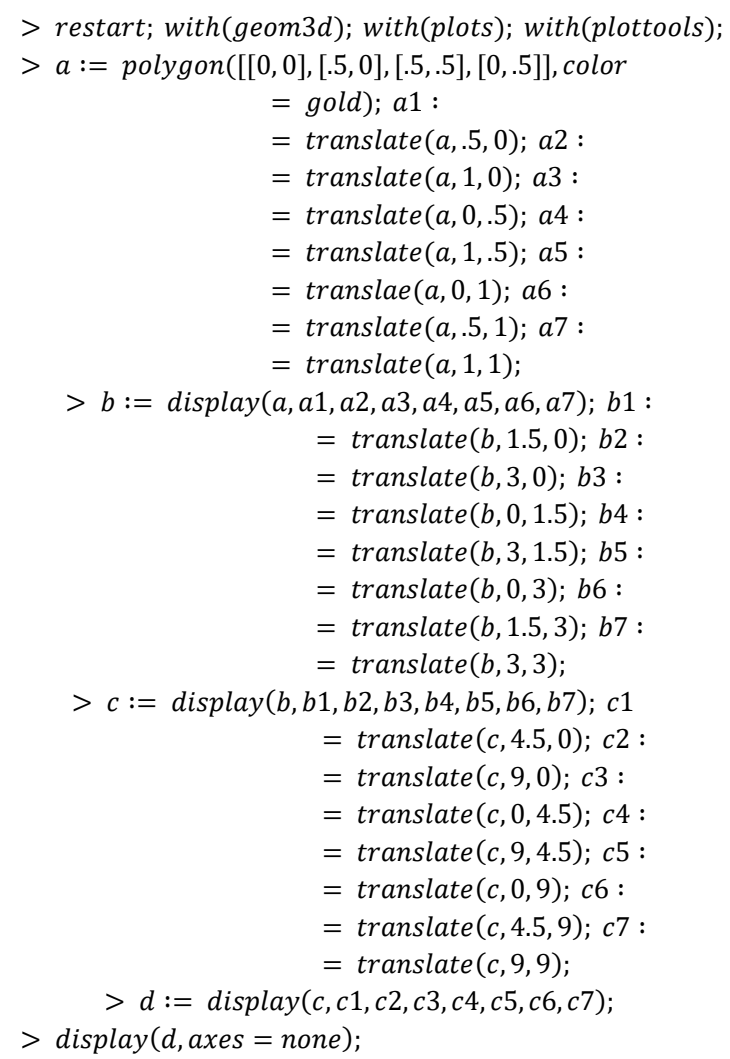

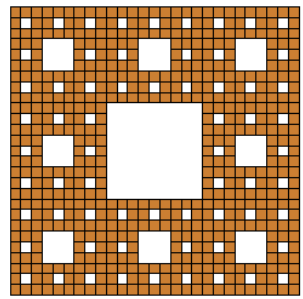

Gambar 2. Bujur Sangkar Sierpinsky

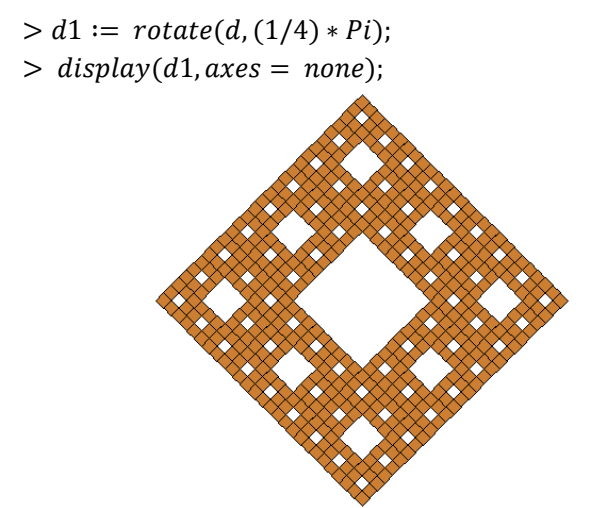

Gambar 3. Bujur Sangkar Sierpinsky (Rotasi 45 ${ }^{\circ}$ )

Pada saat membuat bujur sangkar Sierpinsky, subjek terlihat berpikir dan berupaya menuliskan beberapa rumus rotasi meskipun kemudian menghapusnya dan pada percobaan ketiga sukses. Hal ini sesuai dengan cuplikan wawancara berikut.

\begin{tabular}{|c|c|c|}
\hline$P 11$ & : & $\begin{array}{l}\text { Pada saat membuat bujur } \\
\text { sangkar Sierpinsky ini (peneliti } \\
\text { menunjuk gambar 3) apakah } \\
\text { ada kesulitan? }\end{array}$ \\
\hline$S 1-11$ & : & $\begin{array}{l}\text { Betul pak ... saya ... hemmm } \\
\text { lupa rumus rotasi (yang } \\
\text { dimaksud adalah action script- } \\
\text { nya) }\end{array}$ \\
\hline$P 12$ & : & Ragu maksudnya? \\
\hline$S 1-12$ & : & $\begin{array}{l}\text { Ini lo ... ini pak (sambil } \\
\text { menunjuk layar laptop } d 1:= \\
\operatorname{rotate}(d,(1 / 4) * P i) ;)\end{array}$ \\
\hline P13 & : & Terus \\
\hline$S 1-13$ & : & $\begin{array}{l}\text { Lupa kalau phi itu } 180^{\circ} \\
\text { (sambil tersenyum) }\end{array}$ \\
\hline
\end{tabular}


Berdasarkan hasil pekerjaan subjek dan cuplikan wawancara diperoleh data yang kredibel, sehingga dapat dikatakan bahwa apa yang dikerjakan oleh subjek merupakan hal yang cukup sulit karena dia lupa bahwa Phi adalah $180^{\circ}$. Ini berarti subjek dalam menggambar bujur sangkar Sierpinsky dengan cara mencoba-coba pada bagian rotasi. Jadi antisipasi eksploratif yang digunakan pada masalah ini.

\section{Hiasan Bunga}

S1 membuat hiasan 1 bunga, kemudian di ekspand sampai $\mathrm{K}=3$, dengan rumus ekspand diperkecil kedalam dan di rotasi sebesar $45^{\circ}$.

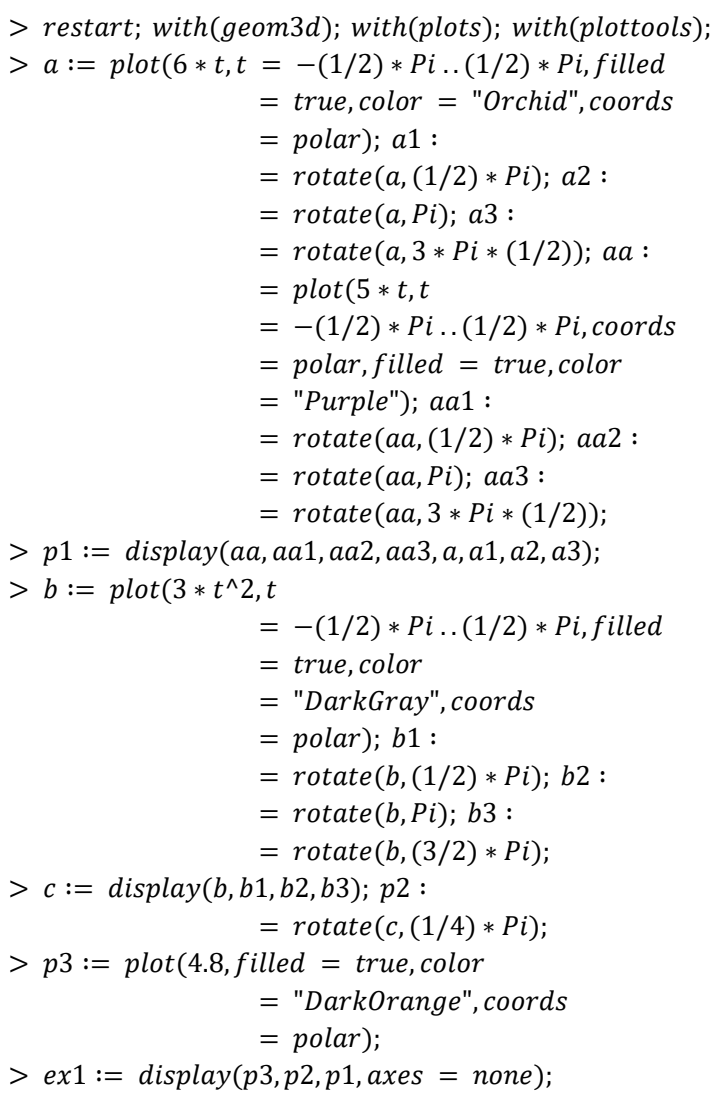

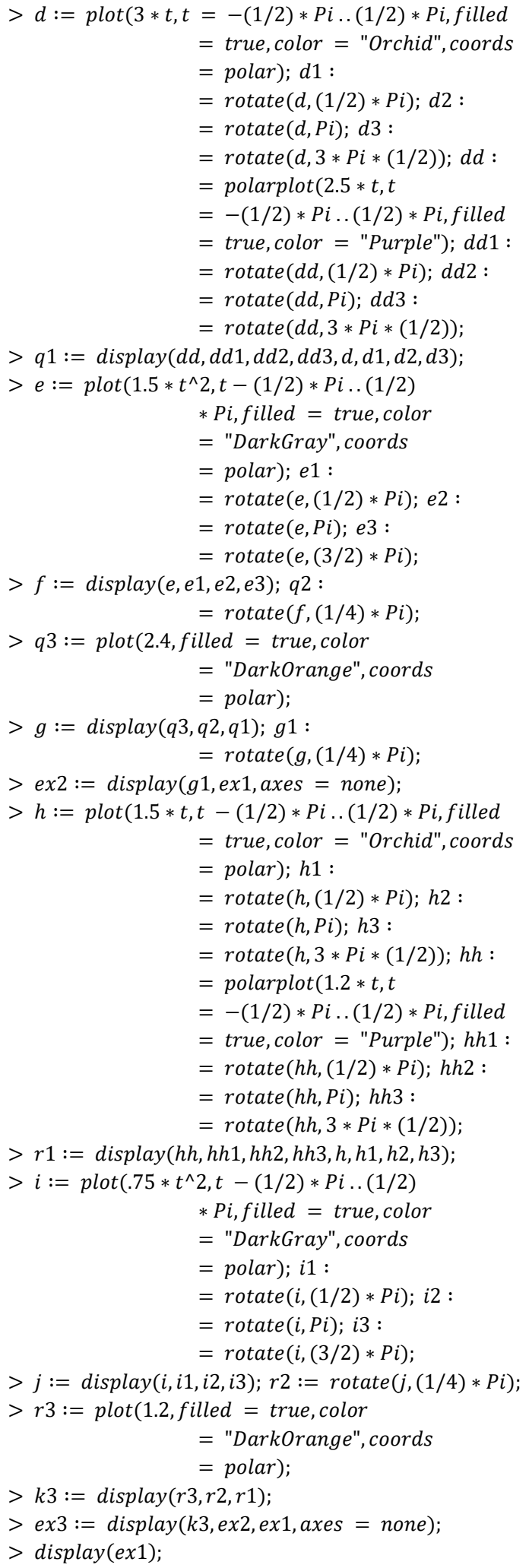




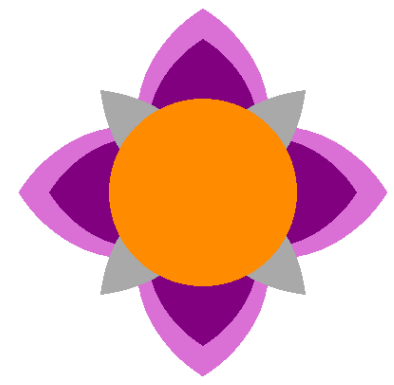

Gambar 4. Desain Bunga Saat Display 1 $>\operatorname{display}(\operatorname{ex2})$

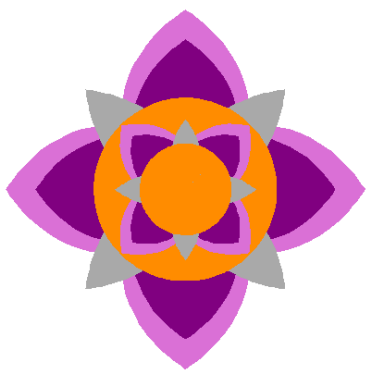

Gambar 5. Desain Bunga Saat Display 2 $>\operatorname{display}(\operatorname{ex3})$;

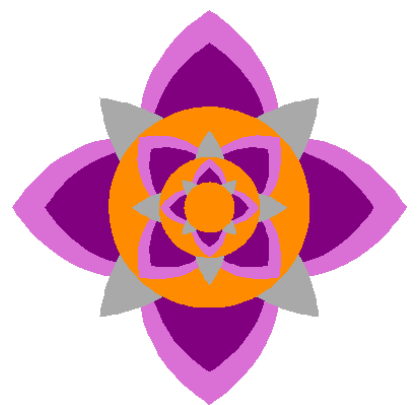

Gambar 6. Desain Bunga Saat Display 3

Pada saat membuat bunga subjek terlihat berpikir sebentar tetapi tidak mengetikkan apa-apa di layar, kemudian sambil menganggukkan kepala (pertanda sudah menemukan apa yang akan ditulis), subjek mulai menuliskan action script panjang sekali. Hal ini sesuai dengan cuplikan wawancara berikut.

\begin{tabular}{|c|c|c|}
\hline$P 22$ & $\therefore$ & $\begin{array}{l}\text { Paham banget ya mas pada } \\
\text { saat ini (menunjuk action } \\
\text { script) sampai mengangguk- } \\
\text { nganggukkan kepala tadi? }\end{array}$ \\
\hline$S 1-22$ & & $\begin{array}{l}\text { Hehehe (tertawa kecil sambil } \\
\text { menunjuk-nunjuk layar) }\end{array}$ \\
\hline & & Nah kok hanya senyum? \\
\hline
\end{tabular}

\section{S1-23 : Iya pak, tadi kan bingung rotasi ... jadi sekarang lancar pak gara-gara tadi}

Berdasarkan hasil pekerjaan subjek dan cuplikan wawancara diperoleh data yang kredibel, sehingga dapat dikatakan bahwa subjek tidak mengalami kendala dalam mengerjakan ini. Tetapi yang menjadi penting di sini, antisipasi sebelumnya (saat membuang bunga) masuk pada kategori antisipasi eksploratif. Ini berarti antisipasi sebelumnya mendukung atau memperbaiki antisipasi setelahnya dengan catatan apa yang dipahami subjek termasuk pada antisipasi analitik.

\section{Sangkar/Wadah dari Hiasan Bunga dan Bujur Sangkar}
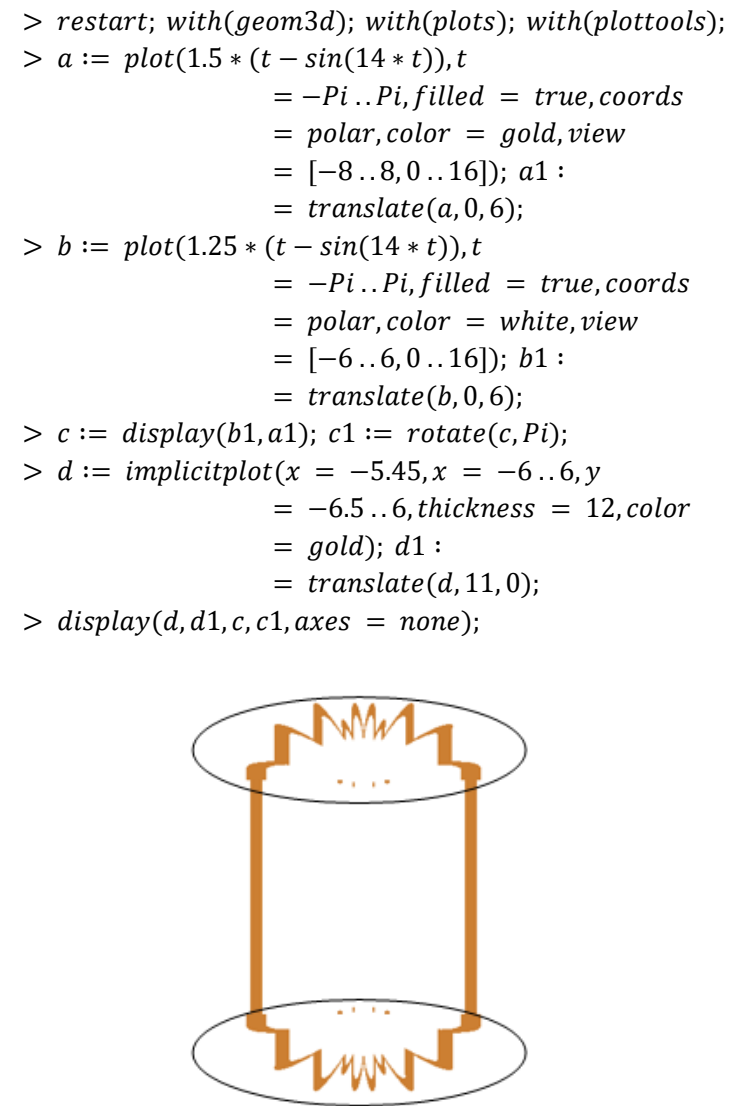

Gambar 7. Desain Sangkar 
Pada saat membuat sangkar subjek terlihat berpikir sebentar dan menunjuknunjuk gambar yang dilingkari pada Gambar 7. Kemudian menuliskan action script dan menghapus, lalu menuliskan lagi kemudian dihapus lagi (sebanyak 4 kali). Hal ini sesuai dengan cuplikan wawancara berikut.

$\begin{array}{ll}\text { P27 } & : \text { Mengapa mas kok dihapus } \\ & \text { terus ( sambil menunjuk } \\ & \text { Gambar 7) } \\ \text { S1-27 } \quad: & \text { Agak rumit ini pak ... (sambil } \\ & \text { mengerutkan dahi) ini ... ini } \\ & \text { kan buat ini (menunjuk gambar } \\ & 7 \text { yang dilingkari). Tapi rumit } \\ & \text { ini pak lalu saya buat sedikit- } \\ & \text { sedikit tetapi tetap tidak jadi } \\ & \text { dan akhirnya jadi. } \\ & \text { Ragu kah mas? Atau tidak } \\ & \text { ditemukan? (memastikan } \\ & \text { apakah subjek sebenarnya } \\ & \text { paham atau tidak cara } \\ & \text { menggambarnya) } \\ & \text { Paham sih pak ... Cuma tadi } \\ & \text { belum pas }\end{array}$

Berdasarkan hasil pekerjaan subjek dan cuplikan wawancara diperolah data yang kredibel, sehingga dapat dikatakan bahwa subjek tidak mengalami kendala berarti dalam mengerjakan ini. Subjek paham apa yang harus dikerjakan tetapi dimungkinkan banyak ide di dalam pikirannya sehingga dia mencoba-coba berulang kali (sebanyak 4 kali) kemudian baru menemukan yang diinginkan. Ini berarti antisipasi yang berperan di bagian ini adalah antisipasi eksploratif.

\section{Heksagon}

Subjek membuat Segitiga Sierpinski, kemudian Segitiga Sierpinski tersebut dirotasi sebesar $180^{\circ}$ dan

\begin{abstract}
ditranslasi sebesar satuan tertentu sedemikian hingga agar Segitiga Sierpinski tersebut membentuk heksagon atau segi enam.
\end{abstract}
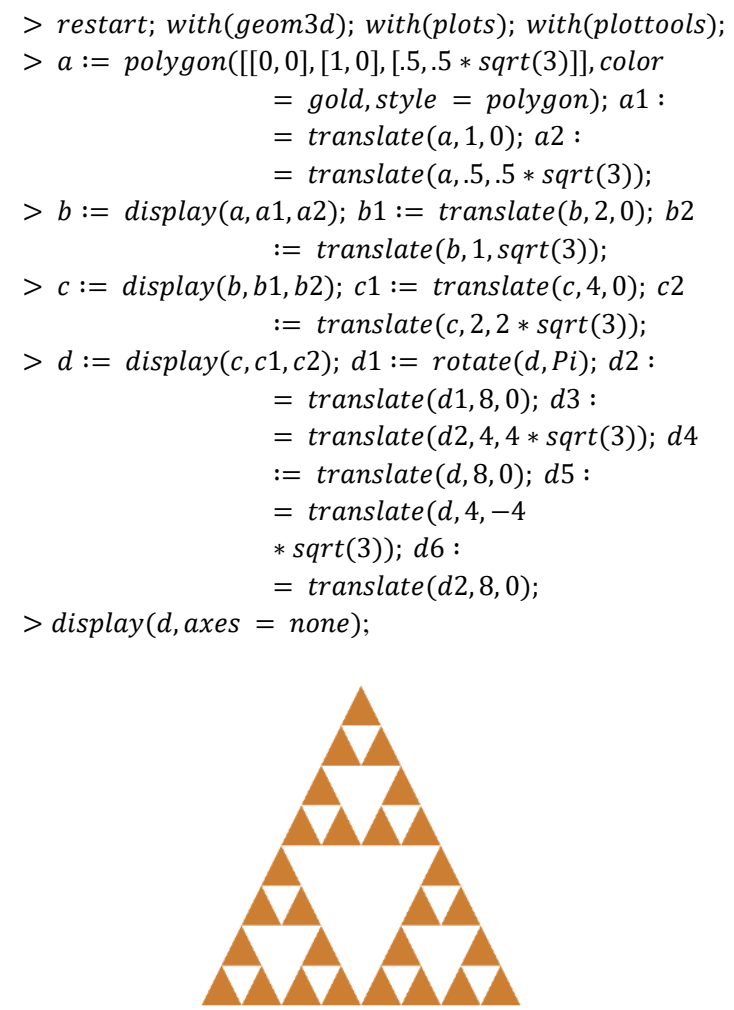

Gambar 8. Segitiga Sierpinsky

$>e:=\operatorname{display}(d, d 2, d 3, d 4, d 5, d 6)$
$>\operatorname{display}(e$, axes $=$ none $)$

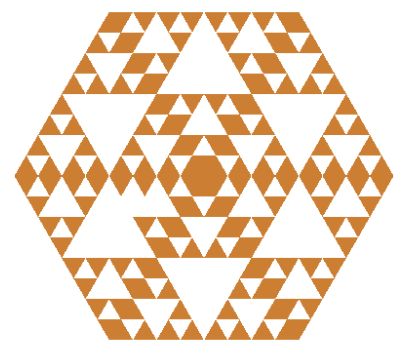

Gambar 9. Hexagon Sierpinsky

Pada saat membuat hexagon, subjek terlihat berpikir sebentar dan mengetikkan action script yang dianggap tepat. Awalnya dia membuat segitiga Sierpinsky kemudian berhenti sejenak lalu melanjutkan membuat 
Hexagon. Hal ini sesuai dengan cuplikan wawancara berikut.

$\begin{array}{lll}\text { P235 } & : & \text { Wah bagus sekali mas. Terlihat } \\ & \text { lancar } \\ \text { S1-35 } \quad: & \text { Betul pak ... ini paham sekali } \\ & \text { saya (terlihat senang) } \\ \text { P36 } & \text { Kenapa kok berpikiran } \\ & \text { membuat bentuk ini? } \\ \text { S1-36 } \quad: & \text { Agar sierpinskynya terlihat } \\ & \text { elegan pak. Hemmm ... kalau } \\ & \text { hanya segitiga itu biasa ... ini } \\ & \text { saya coba buat hexagon. Ini } \\ & \text { kan ... kan lebih elegan pak. }\end{array}$

Berdasarkan hasil pekerjaan subjek dan cuplikan wawancara diperolah data yang kredibel, sehingga dapat dikatakan bahwa subjek tidak mengalami kendala berarti dalam mengerjakan ini. Subjek paham apa yang harus dikerjakan dan ternyata subjek berinovasi dari bentuk asli Sierpinsky dari segitiga menjadi hexagon. Ini berarti antisipasi yang berperan di bagian ini adalah antisipasi analitik.

Langkah selanjutnya yang dikerjakan oleh subjek adalah menggabungkan fungsi-fungsi di atas dan disusun sedemikian hingga menjadi batik seperti terlihat pada Gambar 10.

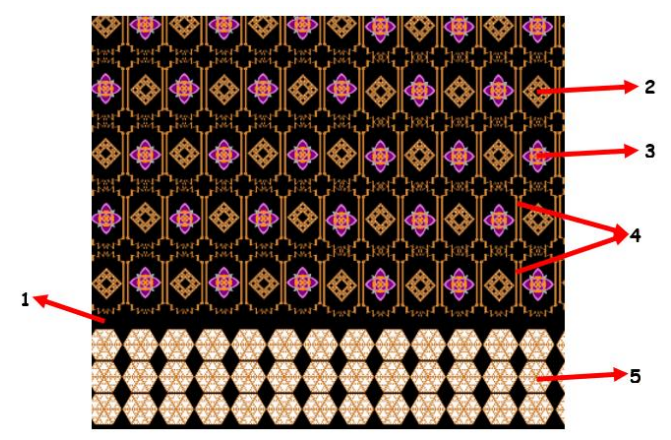

Gambar 10. Batik Bujur Sangkar Sierpinsky

Dari kelima bagian di atas kemudian subjek mengaplikasikan desain akhir dalam bentuk model baju wanita dan pria seperti terlihat pada Gambar 11.

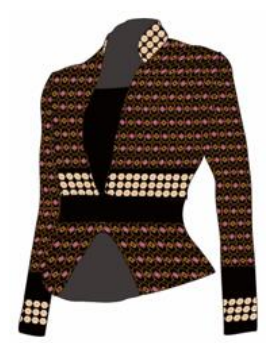

(a)

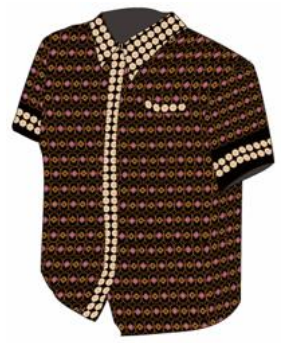

(b)
Gambar 11. (a) Desain Kemeja Wanita dan (b) Laki-laki Menggunakan Hasil Desain Kain Batik Bujur Sangkar Sierpinksy

Berdasarkan hasil pekerjaan subjek, meskipun terbiasa dalam menggunakan software maple tetapi ada beberapa kendala meskipun terlihat tidak berarti pada kegiatan menyelesaikan desain tersebut. Pemamfaatan software maple sangat membantu dalam menyelesaikan masalah-masalah terkait batik dan beberapa lainnya, khususnya masalah visualisasi atau tampilan. Hasil rekapitulasi berdasarkan analisis di atas diperoleh data sebagai berikut.

Tabel 1. Rekapitulasi Objek dan Antisipasi

\begin{tabular}{lll}
\hline No. & \multicolumn{1}{c}{ Objek } & Antisipasi \\
\hline 1. & Background Batik & Analitik \\
2. & Bujur Sangkar & Eksploratif \\
& Sierpinsky & \\
3. & Hiasan Bunga & Analitik \\
4. & Sangkar & Eksploratif \\
5. & Hexagon & Analitik \\
\hline
\end{tabular}

Berdasarkan analisis hasil penelitian ini, diperoleh bahwa dalam menyelesaikan kelima objek tersebut, subjek lebih dominan menggunakan antisipasi analitik. Hal ini berarti subjek meyakini apa yang dikerjakan adalah sesuatu yang benar dan tepat. Menandakan bahwa subjek benar-benar 
memahami apa yang dipikirkan dan dikerjakan. Hal ini sejalan dengan hasil penelitian (Lim, 2007; Sunardi \& Yudianto, 2016; Yudianto, 2015, 2017) yang mengatakan bahwa seseorang yang mengantisipasi secara analitik berarti orang tersebut menganalisis masalah dan menetapkan kriteria untuk tindakan yang artinya mengantisipasi secara analitik adalah mengantisipasi berdasarkan logika yang logis. Hal ini disimpulkan ketika seseorang berusaha memahami pernyataan masalah yang diberikan, mempelajari kendala, mengidentifikasi suatu tujuan yang akan dicapai, membayangkan masalah dan kemudian mempertimbangkan alternatif (Lim, 2006; Riegler, 2001; Yudianto, Suwarsono, \& Juniati, 2017; Yudianto, 2017).

Dalam mengerjakan dua objek lainnya (objek nomor 2 dan 4), subjek mengantisipasi secara eksploratif. Hal ini berarti subjek tidak terlalu yakin menuliskan apa yang dia kerjakan tetapi pada akhirnya memperoleh hasil yang tepat. Menurut Ulmer (2017) mengatakan bahwa antisipasi eksploratif membutuhkan perenungan kembali. Antisipasi eksploratif cenderung spontan tetapi segera menyadari kesalahannya dan memperbaikinya kembali (Tavory \& Eliasoph, 2013).

\section{PENUTUP}

Dalam menyelesaikan desain batik bujur sangkar Sierpinsky, subjek lebih cenderung menggunakan antisipasi analitik dan antisipasi eksploratif dibandingkan ketiga antisipasi yang lain. Rincian antisipasi yang digunakan adalah pada objek 1 terkait background batik, subjek mengantisipasi secara analitik, objek 2. bujur sangkar Sierpinsky subjek mengantisipasi secara eksploratid, objek 3. hiasan bunga, subjek mengantisipasi secara analitik, objek 4. sangkar, subjek mengantisipasi secara eksploratif, dan subjek 5. hexagon subjek mengantisipasi secara analitik. Ini menyimpulkan bahwa subjek dengan kemampuan tinggi cenderung lebih menggunakan dua antisipasi yaitu antisipasi secara analitik dan antisipasi eksploratif.

\section{DAFTAR PUSTAKA}

Asnawati, S., \& Dewi, I. L. K. (2019). Pemahaman Konsep Geometri dan Self Confidence Mahasiswa Calon Guru Matematika pada Mata Kuliah Pembelajaran Mikro untuk Persiapan Pelaksanaan PPL Di Sekolah. Journal of Medives: Journal of Mathematics Education IKIP Veteran Semarang, 3(1), 75. https://doi.org/10.31331/medivesv eteran.v3i1.706

Bramantha, H. (2019). Pengaruh Kemandirian Belajar Terhadap Hasil Belajar Siswa. Journal of Madives, 2(1), 21-28. https://doi.org/10.47971/mjpgmi.v $2 \mathrm{i} 1.63$

Hanifah, \& Abadi, A. P. (2018). Analisis Pemahaman Konsep Matematika Mahasiswa dalam Menyelesaikan Soal Teori Grup kemampuan yang mengharapkan siswa mahasiswa pada program sarjana dan mahasiswa yang akan melanjutkan studi teori-teori dasar dan pembuktian menyebabkan mahasiswa senantiasa. Journal of Medives : Journal of Mathematics Education IKIP Veteran Semarang, 2(2), 235-244. 
Lim, K. H. (2006). Characterizing students' thinking: Algebraic, inequalities and equations. In S. Alatorres, J. . Cortina, M. Saiz, \& A. Mendez (Eds.), Proceedings of the 28th annual meeting of the North American Chapter of the International Group for the Psychology of Mathematics Education (Vol. 2, pp. 102-109). Merida, Mexico: Universidad Pedagógica Nacional.

Lim, K. H. (2007). Students' mental acts of anticipating in solving problems involving algebraic inequalities and equations. Dissertation Abstracts International Section A: Humanities and Social Sciences, 67(7-A), 2501. Retrieved from http://ovidsp.ovid.com/ovidweb.c gi? $\mathrm{T}=\mathrm{JS} \& \mathrm{PAGE}=$ reference $\& \mathrm{D}=\mathrm{p}$ syc $5 \&$ NEWS $=$ N\&AN=200799001-146

Murnaka, N. P., \& Dewi, S. R. (2018). Penerapan Metode Pembelajaran Guided Inquiry untuk Meningkatkan Kemampuan Pemahaman Konsep Matematis. Journal of Medives : Journal of Mathematics Education IKIP Veteran Semarang, 2(2), 163. https://doi.org/10.31331/medives. v2i2.637

Rafianti, I., Iskandar, K., \& Haniyah, L. (2020). Pembelajaran Search, Solve, Create and Share (SSCS) untuk Meningkatkan Pemahaman Konsep dan Disposisi Matematis Siswa. Journal of Medives: Journal of Mathematics Education IKIP Veteran Semarang, 4(1), 97. https://doi.org/10.31331/medivesv eteran.v4i1.980

Riegler, A. (2001). The role of anticipation in cognition. In D. . Dubois (Ed.), Computing
Anticipatory Systems (Vol. 573, pp. 534-541). https://doi.org/10.1063/1.1388719

Rosen. (2010). Robert Rosen's anticipatory systems. Foresight, 12(3), 18-29. https://doi.org/ $10.1108 / 14636681011049848$

Santoso, E., \& Sunendar, A. (2019). Performance Assesment dalam Pembelajaran Berbasis Masalah untuk Meningkatkan Kemampuan Pemahaman Matematik Siswa SMP. Journal of Medives : Journal of Mathematics Education IKIP Veteran Semarang, 3(1), 21. https://doi.org/10.31331/medivesv eteran.v3i1.689

Sunardi, S., \& Yudianto, E. (2016). Antisipasi Siswa Level Analisis Dalam Menyelesaikan Masalah Geometri. AdMathEdu: Jurnal Ilmiah Pendidikan Matematika, Ilmu Matematika Dan Matematika Terapan, 5(2). https://doi.org/ 10.12928/admathedu.v5i2.4776

Tavory, I., \& Eliasoph, N. (2013). Coordinating futures: Toward a theory of anticipation. American Journal of Sociology. https://doi.org/10.1086/668646

Ulmer, M. W. (2017). Anticipation. In Operations Research/ Computer Science Interfaces Series. https://doi.org/10.1007/978-3319-55511-9_5

Yudianto, E., Suwarsono, S., \& Juniati, D. (2017). The Anticipation: How to Solve Problem in Integral? Journal of Physics: Conference Series, $824(1)$. https://doi.org/10.1088/17426596/824/1/012055

Yudianto, E. (2015). Profil antisipasi siswa SMA dalam memecahkan masalah integral. Kreano, 6(1), 
200 | Erfan Yudianto - Anticipation of Student Ideas in Designing Sierpinsky Square Batik Using Maple

21-25.

https://doi.org/http://dx.doi.org/10 .15294/kreano.v6i1.4472

Yudianto, E. (2017). Antisipasi Ide Kreatif Mahasiswa Level Rigor dalam Menentukan Algoritma Benda Ruang Menggunakan Maple. Jurnal Didaktik Matematika, 4(2), 98-106. Retrieved from http://www.jurnal.unsyiah.ac.id/D M/article/view/8369

Yudianto, E. (2019). Pengantar Teori Fraktal dan Aplikasinya. Jember: CV. Pustaka Abadi. 